\title{
Altered $\left[{ }^{99 \mathrm{~m}} \mathrm{Tc}\right] \mathrm{Tc}-\mathrm{MDP}$ biodistribution from neutron activation sourced ${ }^{99} \mathrm{Mo}$
}

\author{
Sandor Demeter ${ }^{1,2} \cdot$ Roman Szweda $^{2,3} \cdot$ Judy Patterson ${ }^{2} \cdot$ Marine Grigoryan $^{3}$
}

Received: 28 December 2017 / Published online: 29 March 2018

(C) The Author(s) 2018

\begin{abstract}
Given potential worldwide shortages of fission sourced ${ }^{99} \mathrm{Mo} /{ }^{99 \mathrm{~m}} \mathrm{Tc}$ medical isotopes there is increasing interest in alternate production strategies. A neutron activated ${ }^{99}$ Mo source was utilized in a single center phase III open label study comparing ${ }^{99 \mathrm{~m}} \mathrm{Tc}$, as ${ }^{99 \mathrm{~m}} \mathrm{Tc}$ Methylene Diphosphonate ([$\left.\left.{ }^{99 \mathrm{~m}} \mathrm{Tc}\right] \mathrm{Tc}-\mathrm{MDP}\right)$, obtained from solvent generator separation of neutron activation produced ${ }^{99} \mathrm{Mo}$, versus nuclear reactor produced ${ }^{99} \mathrm{Mo}$ (e.g., fission sourced) in oncology patients for which an $\left[{ }^{99 \mathrm{~m}} \mathrm{Tc}\right] \mathrm{Tc}-\mathrm{MDP}$ bone scan would normally have been indicated. Despite the investigational $\left[{ }^{99 \mathrm{~m}} \mathrm{Tc}\right] \mathrm{Tc}-\mathrm{MDP}$ passing all standard, and above standard of care, quality assurance tests, which would normally be sufficient to allow human administration, there was altered biodistribution which could lead to erroneous clinical interpretation. The cause of the altered biodistribution remains unknown and requires further research.
\end{abstract}

Keywords Biodistribution $\cdot$ Radiopharmaceutical $\cdot$ Quality control $\cdot$ Neutron activation $\cdot{ }^{99}$ Mo $\cdot$ Pertechnetate

\section{Introduction}

The majority of diagnostic nuclear medicine studies utilize ${ }^{99 \mathrm{~m}} \mathrm{Tc}$ as the base medical isotope. Until very recently over $70 \%$ of the world's supply of ${ }^{99 \mathrm{~m}} \mathrm{Tc}$ 's parent isotope, ${ }^{99} \mathrm{Mo}$, was produced as a fission product in two high enriched uranium (HEU) reactors, i.e., the National Research Universal (NRU) reactor at Chalk River, Canada and the high flux reactor (HFL) in the Netherlands $[1,2]$.

Three major factors have catalyzed a search for alternate sources of ${ }^{99} \mathrm{Mo} /{ }^{99 \mathrm{~m}} \mathrm{Tc}$.

First, both the NRU and HFL reactors are over five decades old and both are nearing, and some would say beyond, their life expectancy. Second, in 2009/10 the world experienced a critical shortage of ${ }^{99} \mathrm{Mo} /{ }^{99 \mathrm{~m}} \mathrm{Tc}$ due to an unplanned shut down of the NRU reactor at the same time

Sandor Demeter

sdemeter@hsc.mb.ca

1 Faculty of Health Sciences, College of Medicine, University of Manitoba, Winnipeg, Canada

2 Section of Nuclear Medicine, Winnipeg Health Sciences Centre, Winnipeg, Canada

3 Radiopharmaceuticals Research Group, Health Sciences Centre, Winnipeg, Canada as planned maintenance down time of the HFL. This was a wakeup call to the world that the existing global production chain could not tolerate such perturbations in supply. Finally, and primarily for nuclear security reasons, the US Department of Energy's National Nuclear Security Administration has mandated a transition from HEU to low enriched uranium (LEU) ${ }^{99} \mathrm{Mo} /{ }^{99 \mathrm{~m}} \mathrm{Tc}$ production [1-7].

Alternate ${ }^{99} \mathrm{Mo} /{ }^{99 \mathrm{~m}} \mathrm{Tc}$ sources include: low enriched uranium fission products, neutron activation (i.e., $\left.{ }^{98} \mathrm{Mo}(\mathrm{n}, \gamma){ }^{99} \mathrm{Mo}\right)$, linear accelerator (e.g., ${ }^{100} \mathrm{Mo}(\gamma, \mathrm{n}){ }^{99} \mathrm{Mo}$ ) and cyclotron (e.g., $\left.{ }^{100} \mathrm{Mo}(\mathrm{p}, 2 \mathrm{n}){ }^{99 \mathrm{~m}} \mathrm{Tc}\right)$ [8-10].

Research was conducted by the prairie isotope production enterprise (PIPE), in Winnipeg, Manitoba, Canada demonstrating proof of principle that neutron activated or LINAC produced ${ }^{99} \mathrm{Mo}$ could be utilized to extract $\left[{ }^{99 \mathrm{~m}} \mathrm{Tc}\right] \mathrm{NaTcO}_{4}$ via liquid-liquid methyl ethyl ketone (MEK) extraction [11]. PIPE then conducted further research to demonstrate commercial viability relative to producing sufficient ${ }^{99} \mathrm{Mo} /{ }^{99 \mathrm{~m}} \mathrm{Tc}$ to meet clinical demands. This later research was to dovetail with a clinical trial.

This paper focuses on the early unexpected results of the clinical trial. 


\section{Experimental}

\section{Radiochemistry}

Procedures for the production of ${ }^{99} \mathrm{Mo}$ by nuclear reactorirradiation at the Missouri University research reactor (MURR, Columbia, MO) and $\left[{ }^{99 \mathrm{~m}} \mathrm{Tc}^{\mathrm{N}}\right] \mathrm{NaTcO}_{4}$ solvent extraction have been previously described $[12,13]$.

\section{Quality control}

The emphasis in this section will focus on the products used in the human clinical trial. For a detailed analysis of ${ }^{99} \mathrm{Mo}$ and ${ }^{99 \mathrm{~m}} \mathrm{Tc}$ quality assurance between MURR and commercial generator sources readers are referred to the article by Grigoryan et al. [11].

\section{Methods}

QC of $\left[{ }^{99 m} \mathrm{Tc}^{\mathrm{NaTCO}}{ }_{4}\right.$ (Pert) eluate for the preparation of The $\left[{ }^{99 \mathrm{~m}} \mathrm{Tc}\right] \mathrm{Tc}-\mathrm{MDP}$

The $\left[{ }^{99 \mathrm{~m}} \mathrm{Tc}\right] \mathrm{NaTcO}_{4}$ (Pert) eluate was analyzed against United States Pharmacopeia (USP) and additional specifications [14].

\section{Radiolabeling of MDP}

$\left[{ }^{99 \mathrm{~m}} \mathrm{Tc}\right] \mathrm{Tc}-\mathrm{MDP}$ was prepared from commercial MDP kits [Edmonton Radiopharmaceutical (15)] by adding 3-12 GBq of freshly eluted Pert to the kit vial. MDP kits were radiolabeled following package insert instruction, and QC performed after reconstitution. A total of $21\left[{ }^{99 \mathrm{~m}} \mathrm{Tc}\right] \mathrm{Tc}$ MDP samples were prepared from 6 different batches of neutron activation sourced sodium molybdate and analyzed for animal (mouse) biodistribution. Four separate batches of radiolabeled MDP were used for the human clinical study.

Radiochemical purity of labeled radiopharmaceutical was evaluated using instant thin layer chromatography (iTLC) strips from BIODEX Medical System Inc. (models 150-001 and 1500-005) with Acetone and distilled water as mobile phases. The $\mathrm{pH}$ of the tagged radiopharmaceutical was determined using the $\mathrm{pH}$ indicator test paper 4.0-7.0 (Merk) and validated with $\mathrm{pH}$ meter (Orion, Thermo Scientific).

\section{Sterility}

BacT/ALERT ${ }^{\circledR}$ Microbial Detection System and culture bottles (BIOMEREUX INC.) were used in qualitative procedures for enhanced recovery and detection of aerobic and facultative microorganisms (bacteria and fungi) in the fresh eluent and $\left[{ }^{99 \mathrm{~m}} \mathrm{Tc}\right] \mathrm{Tc}-\mathrm{MDP}$.

\section{Pyrogen content}

Bacterial endotoxins were quantified by chromogenic methods using point-of-use test system Endosafe ${ }^{\circledR}$-PTS (Charles River Laboratory). Samples were diluted 50 times.

\section{Biodistribution study}

$\left[{ }^{99 m} \mathrm{Tc}\right] \mathrm{Tc}-\mathrm{MDP}$ was administered intravenously $(70-100 \mathrm{MBq}$ in $0.2 \mathrm{~mL})$ in CD1 mice $(n=24)$. The animals were sacrificed at $10 \mathrm{~min}$, and $2 \mathrm{~h}$ post injection and organ tissues were removed, washed and weighted. Radioactivity was determined in a gamma counter (HIDEX AMG Automatic Gamma Counter. The results were expressed as a percent of administered dose/organ.

\section{Results}

\section{QC of neutron activation sourced $\left[{ }^{99 m} \mathrm{Tc} \mathrm{NaTcO}_{4}\right.$ eluate (MURR Pert) for the preparation of $\left[{ }^{99 \mathrm{~m}} \mathrm{Tc}\right] \mathrm{Tc}-\mathrm{MDP}$}

Overall 100 extractions of MURR sourced $\left[{ }^{99 \mathrm{~m}} \mathrm{Tc}\right] \mathrm{NaTcO}_{4}$ (Pert) from 15 batches of sodium molybdate were analyzed.

Results for MURR sourced Pert used for the preparation of MDP samples utilized in clinical trials are summarized in Table 1.

All radio-iTLC results were above the passing 90\% limit, with the majority being well above $95 \%$. Aside from two extractions which had $\mathrm{pH}$ values above passing specifications (Pert from these extractions were not used in the clinical trial), all others were within the USP range of 4.5-7.5. A trend of decreasing $\mathrm{pH}$ with subsequent extractions was observed and the same trend was observed in pertechnetate obtained from the commercial UltraTechnikov $^{\text {TM }}$ V4 generator (Mallinckrodt Pharmaceuticals). All MURR sourced Pert used for the clinical trial passed all quality assurance tests.

${ }^{99}$ Mo breakthrough results for the MURR Pert were all within the passing specification of $<0.15 \mathrm{kBq}{ }^{99} \mathrm{Mo} / \mathrm{MBq}$. Moly breakthrough was typically higher, but always within specification, for the first extraction of the generator and then decreases through subsequent extractions.

Germanium spectra of the pertechnetate obtained from commercial generator, Fig. 1a and MURR Pert, Fig. 1b, and show no significant observable differences. Both show 
Table 1 QC results for MURR $\left[{ }^{99 \mathrm{~m}} \mathrm{Tc}\right] \mathrm{NaTcO}_{4}$ (Pert) used in radiolabeling of MDP for clinical trial ( $n=4$ study participants)

\begin{tabular}{|c|c|c|c|c|c|}
\hline \multirow{2}{*}{$\begin{array}{l}\text { Tests } \\
\text { Lot number }{ }^{\mathrm{a}}\end{array}$} & \multicolumn{4}{|l|}{ Results } & \multirow[t]{2}{*}{ Specifications } \\
\hline & M13-16-004 & M13-16-007 & M13-16-008 & M14-16-002 & \\
\hline \multicolumn{6}{|l|}{ Radiochemical purity } \\
\hline Radio-iTLC & $99.55 \%$ & $99.5 \%$ & $99.55 \%$ & $99.37 \%$ & $>90 \%$ \\
\hline Moly breakthrough & 0.00 & 0.00 & 0.00 & 0.00 & $<0.15$ \\
\hline \multicolumn{6}{|l|}{ Chemical purity } \\
\hline Aluminum test & Pass & Pass & Pass & Pass & $<10 \mu \mathrm{g}$ \\
\hline Iodoform & Pass & Pass & Pass & Pass & $<0.1 \%(\mathrm{v} / \mathrm{v})$ \\
\hline Sterility & Pass & Pass & Pass & Pass & pass/fail \\
\hline Pyrogenicity & Pass & Pass & Pass & Pass & pass/fail \\
\hline $\mathrm{pH}$ & 6.34 & 5.39 & 5.47 & 6.05 & $4.5-7.5$ \\
\hline
\end{tabular}

${ }^{\mathrm{a}}$ Perts used for radiolabeling MDP for patients main peak at $140 \mathrm{keV}$ and summation peak of $280 \mathrm{keV}$, which corresponds to ${ }^{99 \mathrm{~m}} \mathrm{Tc}$, with no other significant peaks (both samples immediately after extraction, i.e. $0 \mathrm{~h}$ ).

All extractions of pertechnetate passed sterility and pyrogenicity tests.

\section{Radiolabeling of MDP}

A total of 21 preparations of MDP using MURR Pert were made which include the 4 radiolabeled products used in the clinical trial (Table 2).

Passing specification for $\left[{ }^{99 \mathrm{~m}} \mathrm{Tc}\right] \mathrm{Tc}-\mathrm{MDP}$ radio-iTLC is $\geq 90 \%$. The majority of the acetone and water radioiTLC results were $>95 \%$ and were similar to results for radiolabeled MDP when pertechnetate from a commercial generator was used. All radiolabeled MDPs had the $\mathrm{pH}$ values within the passing specifications of 6-6.5.

\section{Sterility and pyrogenicity}

Each extraction of MURR Pert passed tests for sterility and pyrogenicity and all radiolabeled MDPs passed sterility tests.

\section{Animal biodistribution study}

$\left[{ }^{99 m} \mathrm{Tc}\right] \mathrm{Tc}-\mathrm{MDP}$ at (standard dose of 70-100 MBq) was administered by intravenous tail injection into 24 CD1 mice. Institutional ethical approval ${ }^{1}$ was obtained for the animal study.

Animals were sacrificed at $10 \mathrm{~min}, 2$, and $4 \mathrm{~h}$ post injection and dissected to measure the percent of total activity in each organ using a HIDEX Gamma counter.

\footnotetext{
1 The University of Winnipeg Animal Care Committee protocol\#: AE04358 Institution Approval: 17 February 2015.
}

There were four mice $(n=4)$ done at each time point for both MURR $\left[{ }^{99 m} \mathrm{Tc}\right] \mathrm{Tc}-\mathrm{MDP}$ and for commercial $\left[{ }^{99 \mathrm{~m}} \mathrm{Tc}\right]$ Tc-MDP as illustrated in Fig. $2 \mathrm{a}, \mathrm{b}$ and $\mathrm{c}$.

Biodistribution of the MDP is very similar between the two sets of radiopharmaceuticals (MURR and commerical or HSC). Both show a gradual uptake of MDP into the GI tract as time progresses; however with a relative trend of increasing large bowel uptake of MDP for the MURR MDP injected mice.

A two tail Students $t$ test for independence was used to compare organ/tissue uptake at $10 \mathrm{~min}$ and 2 and $4 \mathrm{~h}$ after tail vein injection. Significant differences, at the $p \leq 0.05$ level, were generally scattered and inconsistent. Results are presented in Fig. 3.

The MURR MDP had significantly decreased femur uptake at $10 \mathrm{~min}$ and $2 \mathrm{~h}$ but not at $4 \mathrm{~h}$. MURR MDP had significantly increased spine uptake at $2 \mathrm{~h}$ but not at the other time points. Relative to the human imaging findings it is notable that the MURR product had significantly increased relative activity in the large intestine at both 2 and $4 \mathrm{~h}$.

\section{Clinical trial}

The trial was a prospective single center phase III open label study comparing ${ }^{99 \mathrm{~m}} \mathrm{Tc}$, as ${ }^{99 \mathrm{~m}} \mathrm{Tc}$ Methylene Diphosphonate ([ $\left.\left.{ }^{99 \mathrm{~m}} \mathrm{Tc}\right] \mathrm{Tc}-\mathrm{MDP}\right)$, obtained from solvent generator separation of neutron activation produced ${ }^{99} \mathrm{Mo}$, versus nuclear reactor produced ${ }^{99} \mathrm{Mo}$ (e.g., fission sourced) in oncology patients for which an $\left[{ }^{99 \mathrm{~m}} \mathrm{Tc}\right] \mathrm{Tc}-$ MDP bone scan would normally have been indicated. The study participants acted as their own controls (i.e., standard of care bone scan first followed by MURR [ ${ }^{99 \mathrm{~m}} \mathrm{Tc}$ ]Tc-MDP in same patient 3-28 days later). The clinical study was approved by Health Canada and the institutional Research Ethics Board and is listed as "terminated" in https:// 

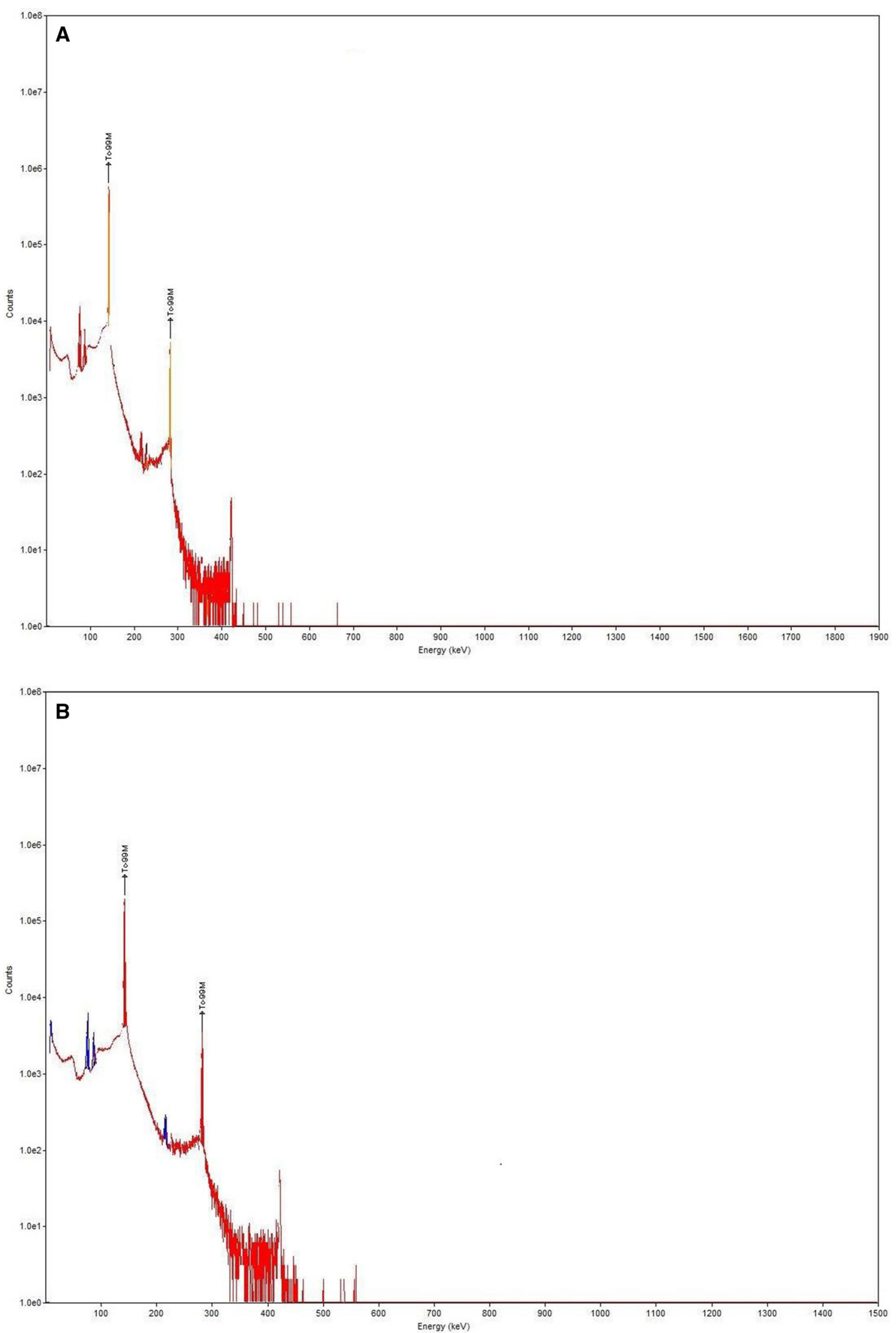
4Fig. 1 Gamma-spectra of sodium pertechnetate extracted from: a A commercial Ultra-Technikov ${ }^{\mathrm{TM}}$ V4 generator (Mallinckrodt Pharmaceuticals) used in the Radiopharmacy department of Health Sciences. b The primary source ${ }^{99} \mathrm{MoO}_{4}{ }^{2-}$ solution produced by dissolving nuclear reactor-irradiated sintered ${ }^{99}$ Mo discs (MURR)

clinicaltrials.gov/ under the trial registration number NCT03002454.

\section{Inclusion criteria}

1. Male or female patient oncology out-patients in which a standard of care $\left[{ }^{99 \mathrm{~m}} \mathrm{Tc}\right] \mathrm{Tc}-\mathrm{MDP}$ bone scan has been already been obtained.

2. If female of child-bearing potential is outside of the window of 10 days since the last menstrual period, a negative serum or urine pregnancy test is required.

3. Age greater than or equal to 18 years.

4. Able and willing to follow instructions and comply with the protocol.

5. Deemed competent to provide written informed consent prior to participation in this study.

\section{Exclusion criteria}

1. Nursing or pregnant females.

2. Age less than 18 years.

3. No written consent provided.

4. Interval since a prior bone scan less than 3 days or greater than 3 weeks.

5. Identified interval event which could influence/change bone scan uptake (e.g., skeletal trauma, orthopedic surgery, bone infection, or interval therapy (i.e., radiation therapy, non-maintenance chemotherapy).

6. Initial bone scan of suboptimal diagnostic quality relative to non-radiopharmaceutical factors such as, partially interstitial injection or alternated image acquisition parameters (e.g., off peak acquisition).

7. Patients who exceed the safe weight limit of the scanner bed.

8. Patients who have experienced an adverse reaction to fission sourced $\left[{ }^{99 \mathrm{~m}} \mathrm{Tc}\right] \mathrm{Tc}-\mathrm{MDP}$.
9. Patients who are deemed not be able to tolerate the imaging procedure (e.g., cannot lie still for the duration of image acquisition).

Up to 50 patients were to be enrolled. (Sample size parameters included: anticipated lesion prevalence $-30 \%$, $\left[{ }^{99 \mathrm{~m}} \mathrm{Tc}\right] \mathrm{Tc}-\mathrm{MDP}$ sensitivity $90 \%$, powered to detect a Kappa of 0.7 for visual equivalence between the set of images $[15,16])$.

A set of experienced Canadian Royal College of Physicians and Surgeons certified Nuclear Medicine physicians were to be presented with paired anterior and posterior whole body planar images labeled "A" and "B" representing the neutron activated and commercial generator sourced ${ }^{99} \mathrm{Mo} /{ }^{99 \mathrm{~m}} \mathrm{Tc}$ (randomly assigned to "A" or "B"). The readers were to be presented only with the image data sets and were to be blinded as to the order of the paired images.

\section{Imaging protocol}

Administered ${ }^{99 \mathrm{~m}} \mathrm{Tc} \quad$ Methylene Diphosphonate $\left(\left[{ }^{99 \mathrm{~m}} \mathrm{Tc}\right] \mathrm{Tc}-\mathrm{MDP}\right)$ doses were $750 \mathrm{MBq}( \pm 10 \%)$. Imaging parameters were the site's standard dual head whole body bone scan settings which were aligned between the standard of care and the investigational agent bone scans (e.g., specific gamma camera, time between injection and imaging acquisition settings). Two patients were imaged on a Siemens Symbia T6 and two on a GE Hawkeye Infinia systems.

\section{Results}

The trial was terminated after the first 4 patients were enrolled due to gross altered biodistribution between the two sets of images. This was noted by the study principal investigator when the image data sets were being prepared for the expert readers. These patients were recruited in a 2 week period and included the investigational agent from two separate neutron activated ${ }^{99}$ Mo shipments. There were two females and two males recruited with an average
Table 2 QC results for radiolabeled MDP used in clinical trials

\begin{tabular}{lllll}
\hline Lot\# & $\mathrm{pH}$ (spec. 6.0-6.5) & \multicolumn{2}{l}{ Radio-iTLC (spec. > 90\%) } & \multirow{2}{*}{ Sterility } \\
\cline { 3 - 4 } & & Acetone $(\%)$ & Water $(\%)$ & \\
\hline MURR13-MDP1 & 6.29 & 98.49 & 99.17 & Pass \\
MURR13-MDP2 & 6.16 & 99.55 & 98.90 & Pass \\
MURR13-MDP3 & 6.19 & 99.27 & 98.32 & Pass \\
MURR14-MDP1 & 6.30 & 95.60 & 98.60 & Pass \\
\hline
\end{tabular}


Fig. 2 Biodistribution (\%ID/g) of MURR [ $\left.{ }^{99 \mathrm{~m}} \mathrm{Tc}\right] \mathrm{Tc}-\mathrm{MDP}$ and commercial $\left[{ }^{99 \mathrm{~m}} \mathrm{Tc}\right] \mathrm{Tc}-\mathrm{MDP}$ at various time points: a $10 \mathrm{~min}$; b $2 \mathrm{~h}$; c $4 \mathrm{~h}$. Sample size for each timpoint were $n=4$ for injection. The timepoints shown represent the time after administration of the dose
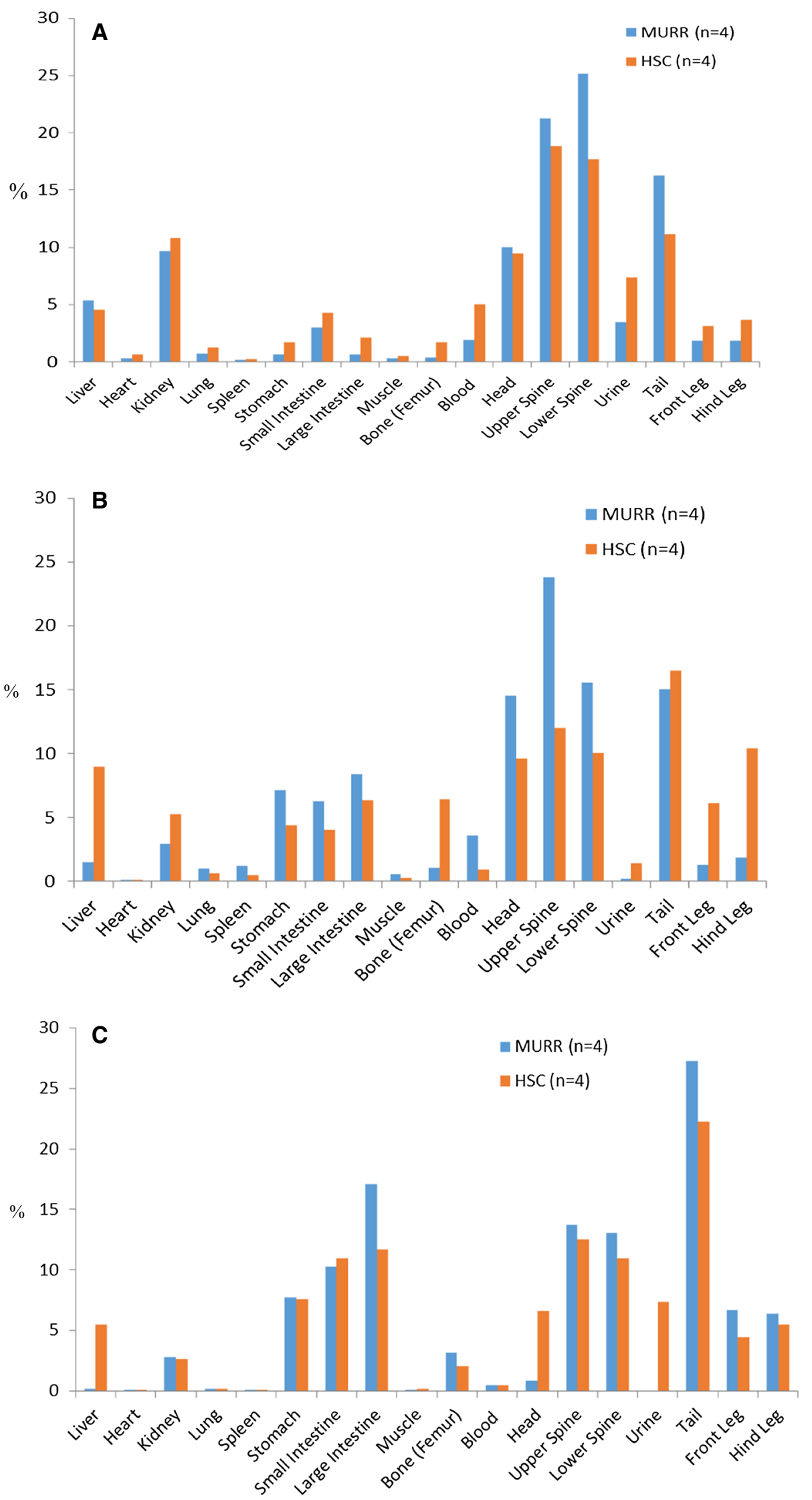


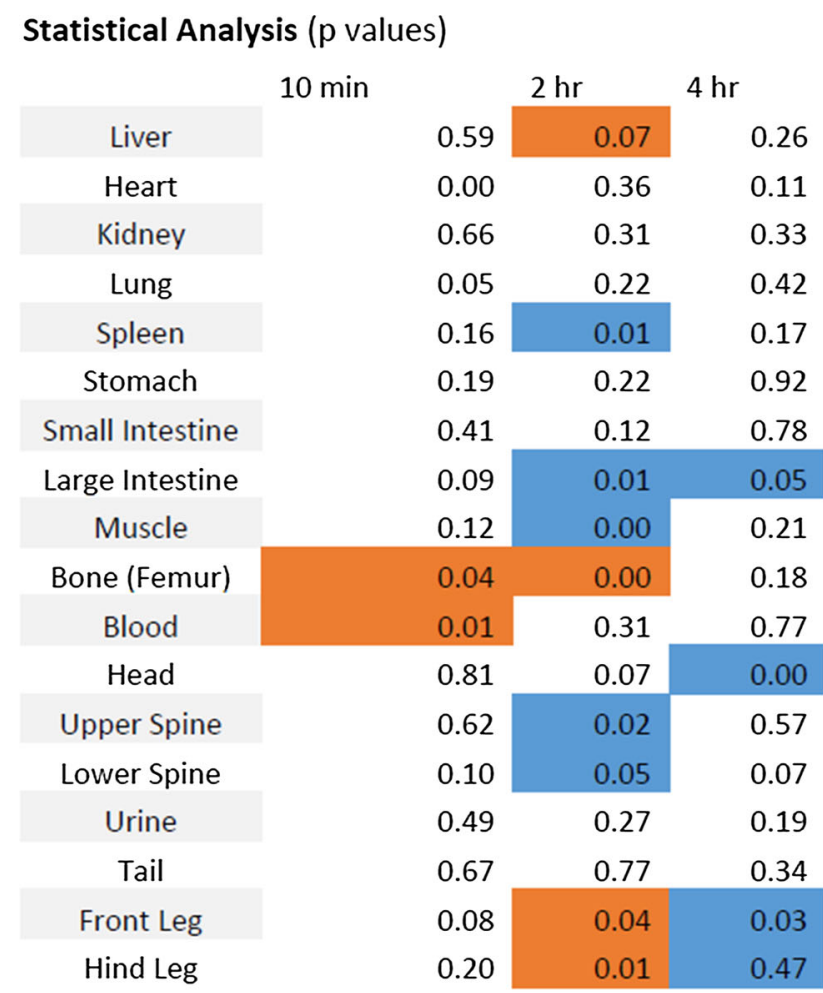

T test for two independent samples, two tail, nonequal variances, threshold $\mathrm{p} \leq 0.05$

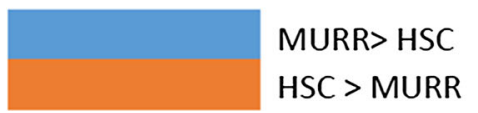

Fig. 3 Two tail Students $t$ test for independence results comparing organ/tissue uptake at $10 \mathrm{~min}$ and 2 and $4 \mathrm{~h}$ after mouse tail vein injection ( $n=4$ mice for each timepoint)

age of 60.5 and pathologies included: prostate cancer $(n=2)$, breast cancer $(n=1)$ and uterine cancer $(n=1)$.

Figure $4 \mathrm{a}-\mathrm{d}$, illustrates consistent altered biodistribution of "bowel like" uptake (arrow) in the right lower quadrant for the four participants (standard of care bone scan on the left and investigational agent on the right).

After a chart review there were no protocol breaches for these participants, no significant interval interventions, no acute symptomatic episodes, and no known interfering medications to account for the findings.

To reiterate, and add to, the previous section, the MURR $\left[{ }^{99 m} \mathrm{Tc}\right] \mathrm{Tc}-\mathrm{MDP}$ passed all quality control parameters including some beyond standard of care testing (e.g., radioiTLC (Pert and MDP), pH (Pert and MDP), Germanium spectroscopy (Pert), ${ }^{99}$ Mo breakthrough, and mass spectroscopy (Pert).

\section{Discussion}

Elution of generator and radiolabeling of commercial MDP was performed by experienced technologists according to existing SOP's. Proper handling procedures were proven many times during regular Radiopharmacy production. Intervals between Pert elution were less than $24 \mathrm{~h}$ to minimize formation of ${ }^{99} \mathrm{Tc}$ (i.e., cold pert) that can compete with ${ }^{99 \mathrm{~m}} \mathrm{Tc}$ for stannous reduction and chelation reactions. All product used in the clinical trial were prepared as specified in the commercial MDP kit monograph.

Radiation can interact with water molecules forming ions, free radicals and peroxides particularly at higher activities and is well described [17-19]. Peroxides and hydroxyl free radicals are capable of oxidizing stannous ion and interact with technetium complexes to cause decomposition and oxidation of reduced technetium resulting in production of free Pert, noting that there was no evidence of free Pert on the study participants images. Peroxides tend to build up over time and may be present in the eluate from a generator with prolonged in-growth time, or Pert aged for several hours since elution. However, ascorbic acid that is present in the MDP kit should substantially reduce radiolytic decomposition.

Galea et al. [20] published on animal [ $\left.{ }^{99 \mathrm{~m}} \mathrm{Tc}\right] \mathrm{Tc}-\mathrm{MDP}$ and Tetrofosmin imaging using ${ }^{99 \mathrm{~m}} \mathrm{Tc}$ derived from either a commercial ${ }^{99} \mathrm{Mo}$ generator or a linear accelerator (LINAC) source (i.e., 100Mo $\left.(\gamma, \mathrm{n}){ }^{99} \mathrm{Mo}\right)$. No abnormal bowel uptake was noted for the LINAC sourced $\left[{ }^{99 \mathrm{~m}} \mathrm{Tc}\right] \mathrm{Tc}$ MDP although there was altered renal uptake in the nonbuffered versus the buffered versions thought to be related to gluconate impurities.

This the first known publication demsontrating altered biostribution from neutron activated sourced $\left[{ }^{99 \mathrm{~m}} \mathrm{Tc}\right] \mathrm{Tc}-$ MDP in humans.

\section{Conclusion}

This study illustrates the importance of being vigilant and managing unexpected findings when conducting a clinical trial. Despite the investigational agent passing all standard, and above standard of care, quality assurance tests, which would normally be sufficient to allow human administration, there was altered biodistribution which could lead to erroneous clinical interpretation. The cause of the altered biodistribution remains unknown and requires further research. 
A
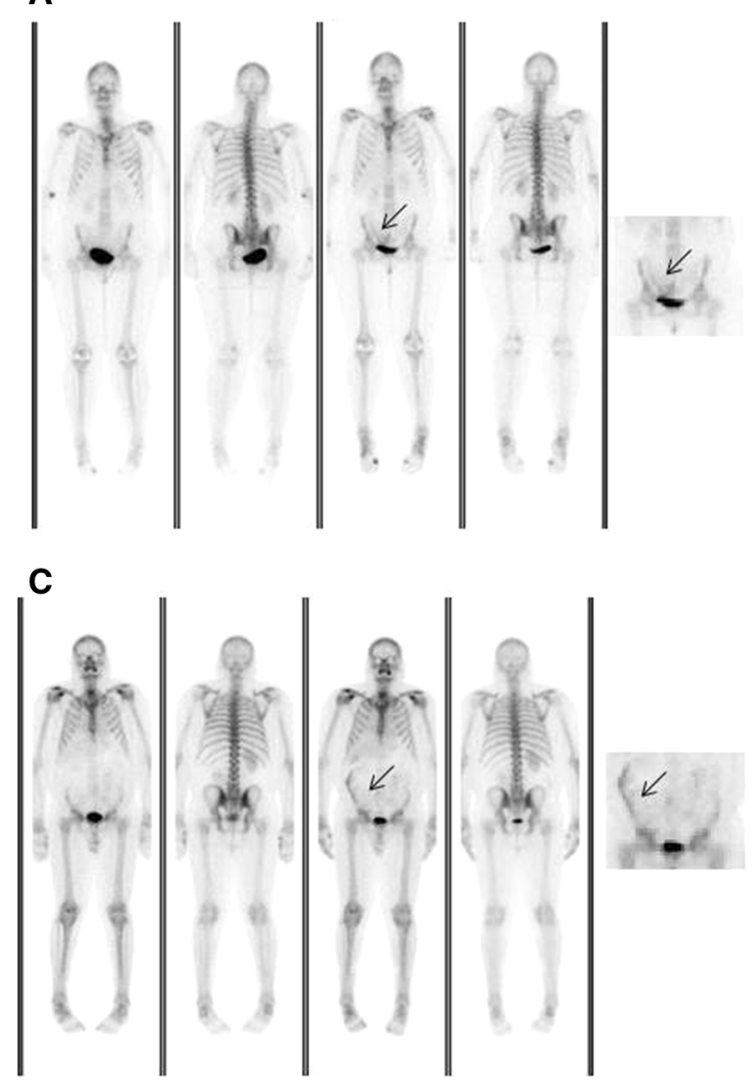

Fig. 4 a-d Whole body bone scans of patients enrolled in the study. The left panel for each patient utilized commercial $\left[{ }^{99 \mathrm{~m}} \mathrm{Tc}\right] \mathrm{Tc}-\mathrm{MDP}$ and the right panel utilized MURR $\left[{ }^{99 \mathrm{~m}} \mathrm{Tc}\right] \mathrm{Tc}-\mathrm{MDP}$. An enlarged

Acknowledgements This research was partly supported by funding from Natural Resources Canada under the Non-Reactor Isotope Supply Program and the Isotope Technology Acceleration Program as well as by the Canadian Institute of Health Research (CIHR) Medical Imaging Trial Network of Canada. The Winnipeg HSC Radiopharmaceuticals Research Group is acknowledged for their contributions to this research.

Open Access This article is distributed under the terms of the Creative Commons Attribution 4.0 International License (http://creative commons.org/licenses/by/4.0/), which permits unrestricted use, distribution, and reproduction in any medium, provided you give appropriate credit to the original author(s) and the source, provide a link to the Creative Commons license, and indicate if changes were made.

\section{References}

1. Van Noorden R (2013) The medical testing crisis. 503: 202-204 http://www.nature.com/news/radioisotopes-the-medical-testingcrisis-1.14325

2. Ruth TJ (2014) The medical isotope crisis: how we got here and where we are going. J Nucl Med Technol 42(4):245-248. https:// doi.org/10.2967/jnmt.114.144642
B
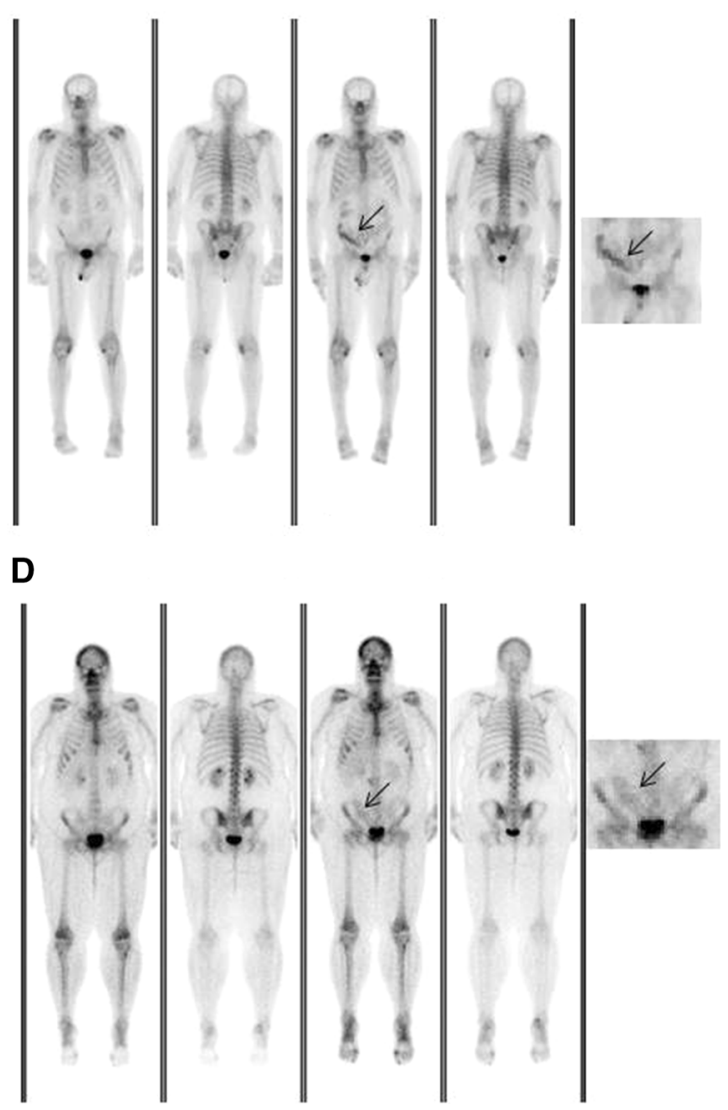

image of the pelvis from the right panel better illustrating the altered biodistribution is provided on the right of each image set

3. Pillai MRA, Dash A, Knapp FF Jr (2013) Sustained availability of ${ }^{99 \mathrm{~m}} \mathrm{Tc}$ : possible paths forward. J Nucl Med 54:313-323. https://doi.org/10.2967/jnumed.112.110338

4. Pillai MRA, Dash A, Knapp FF Jr (2015) Diversification of ${ }^{99} \mathrm{Mo} /{ }^{99 m} \mathrm{Tc}$ separation: non-fission reactor production of ${ }^{99} \mathrm{Mo}$ as a strategy for enhancing ${ }^{99 \mathrm{~m}} \mathrm{Tc}$ availability. J Nucl Med 56:159-161. https://doi.org/10.2967/jnumed.114.149609

5. Government of Canada. Library of the Parliament. Parliamentary Information and Research Service. The medical isotope shortage: cause, effects and options. In: Zakzouk $M$ (ed) The medical isotope shortage: cause, effects and options. Industry, Infrastructure and Resources Division, Revised 1 September 2009. PRB 09-04E

6. Cutler CS, Schwarz SW (2014) Diversification in the supply chain of ${ }^{99}$ Mo Ensures a Future for ${ }^{99 \mathrm{~m}}$ Tc. J Nucl Med 55:1-6. https://doi.org/10.2967/jnumed.113.131953

7. GTRI: reducing nuclear threats-fact sheet (April 12, 2013). http://nnsa.energy.gov/mediaroom/factsheets/reducingthreats

8. Khandaker MU, Uddin MS, Kim KS, Lee YS, Kim GN (2007) Measurement of cross-sections for the $(\mathrm{p}, \mathrm{xn})$ re-actions in natural molybdenum. Nucl Instrum Methods Phy Res B 262(2):171-181. https://doi.org/10.1016/j.nimb.2007.05.028

9. Uddin MS, Hagiwara M, Tarkanyl F, Ditroiland F, Baba M (2004) Investigation of the proton-induced activation reactions on natural molybdenum. JAERI-Conf. http://www.iaea.org/inis/col lection/NCLCollectionStore/_Public/36/116/36116681.pdf 
10. Pillai MRA, Dash A, Knapp FF Jr (2013) Sustained availability of ${ }^{99 \mathrm{~m}} \mathrm{Tc}$ : possible paths forward. J Nucl Med 54(2):313-323. https://doi.org/10.2967/jnumed.112.110338 Epub 2012 Dec 19

11. Grigoryan M, Fitzpatrick J, Mangera K (2016) Evaluation of the radionuclidic product profiles of natural molybdenum irradiated using linear accelerator and nuclear reactor technology. J Radioanal Nucl Chem. https://doi.org/10.1007/s10967-016-4901-7

12. Zriba R, Mangera K, Fitzpatrick J, Brown JJ, Pellerin E, Barnard J, Saunders C (2014) Solvent extraction of ${ }^{99 m} \mathrm{Tc}$ from ${ }^{98} \mathrm{Mo}(\mathrm{n}$, $\gamma)^{99} \mathrm{Mo}{ }^{99} \mathrm{Mo}$, and its evaluation for labeling of radiopharmaceutical kits. J Nucl Med 55(supplement 1):1145

13. Billinghurst MW, Abrams DN, Dupont J (1992) A comparison of radiopharmaceutical labelling efficiency of chromatographic generator versus MEK extraction $\left[{ }^{99 \mathrm{~m}} \mathrm{Tc}\right]$ pertechnetate. Int $\mathbf{J}$ Radiat Appl Instrum 43(8):1045-1049

14. Jun BJ, Tanimoto M, Kimura A, Hori N, Izumo H, Tsuchiya $\mathrm{K}$ (2010) Table 2. Neutron irradiation and testing reactor center, Oarai research and development center. Feasibility study on mass production of $(\mathrm{n}, \gamma)^{99}$ Mo. JAEA-Research 2010-046 http://
jolissrch-inter.tokai-sc.jaea.go.jp/pdfdata/JAEA-Research-2010046.pdf. Accessed 28 Apr 2017

15. MDP-10, KIT for the Preparation of ${ }^{99 \mathrm{~m}}$ Tc Medronate, Edmonton Radiopharmaceutical Centre (2006)

16. Sim J, Wright CC (2005) The Kappa statistic in reliability studies: use, interpretation, and sample size requirements. Phys Ther 85:257-268

17. Billinghurst MW, Remple S, Westendorf BA (1979) Radiation decomposition of ${ }^{99 \mathrm{~m}} \mathrm{Tc}$ radiopharmaceuticals. J Nucl Med 20:138-143

18. Molinski VJ (1982) A review of ${ }^{99 \mathrm{~m}}$ Tc generator technology. Int J Appl Radiat Isot 33:811-819

19. Kishore R (1979) Radiation decomposition of ${ }^{99 \mathrm{~m}} \mathrm{Tc}$ radiopharmaceuticals. J Nucl Med 20:999-1000

20. Galea R, Wells RG, Ross CK, Lockwood J, Moore K et al (2013) A comparison of rat SPECT images obtained using ${ }^{99 \mathrm{~m}} \mathrm{Tc}$ derived from ${ }^{99}$ Mo produced by an electron accelerator with that from a reactor. Phys Med Biol 58:2737-2750 